\title{
Study of the collagen type VI alpha 3 (COL6A3) gene in Parkinson's disease
}

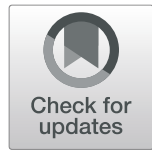

\author{
Chong-Yao Jin ${ }^{\dagger}$, Ran Zheng ${ }^{\dagger}$, Zhi-Hao Lin, Nai-Jia Xue, Ying Chen, Ting Gao, Yi-Qun Yan, Yi Fang, Ya-Ping Yan, \\ Xin-Zhen Yin, Jun Tian, Jia-Li Pu* and Bao-Rong Zhang*
}

\begin{abstract}
Background: To date, the genetic contribution to Parkinson's disease (PD) remains unclear. Mutations in the collagen type $\mathrm{VI}$ alpha 3 (COL6A3) gene were recently identified as a cause of isolated dystonia. Since PD and dystonia are closely related disorders with shared clinical and genetic characteristics, we explored the association between COL6A3 and PD in a Chinese cohort.

Methods: We performed genetic screening of COL6A3 in a Chinese cohort of 173 patients with sporadic PD and 200 healthy controls. We identified variants that are likely to have pathogenic effects based on: 1) a minor allele frequency of $<0.01$; and 2) the variant being recognized as deleterious by at least 15 different in silico predicting tools. Finally, we tested the aggregate burden of COL6A3 on PD via SKAT-O analysis.

Results: First, we found compound heterozygous COL6A3 gene mutations in one early-onset PD patients. Then, we explored whether COL6A3 variants contributed to increased risk of developing PD in a Chinese population. We detected 21 rare non-synonymous variants. Pathogenicity predictions identified 7 novel non-synonymous variants as likely to be pathogenic. SKAT-O analysis further revealed that an aggregate burden of variants in COL6A3 contributes to PD $(p=0.038)$.
\end{abstract}

Conclusion: An increased aggregate burden of the COL6A3 gene was detected in patients with PD.

Keywords: Parkinson's disease, Dystonia, Gene, COL6A3

\section{Background}

Parkinson's disease (PD) is the second most common neurodegenerative disease in the world, affecting approximately $2-3 \%$ of the population $\geq 65$ years of age $[1$, $2]$. The disease is characterized by multiple symptoms, grouped as motor symptoms such as bradykinesia, resting tremor and rigidity [3], and non-motor symptoms such as depression, apathy and sleep disorders [4]. The precise cause of PD is currently unknown, although scientists generally believe that it is a result of both genetic and environmental factors.

\footnotetext{
* Correspondence: jialipu@zju.edu.cn; brzhang@zju.edu.cn

${ }^{\dagger}$ Chong-Yao Jin and Ran Zheng contributed equally to this work. Department of Neurology, Second Affiliated Hospital, College of Medicine,

Zhejiang University, Hangzhou, Zhejiang 310009, People's Republic of China
}

The collagen type VI alpha 3 (COL6A3) gene, encoding the collagen alpha-3(VI) chain, is recognized as being associated with muscular dystrophy [5]. Recently, Zech et al. found that loss-of-function mutations of COL6A3 cause autosomal recessive isolated dystonia [6], a movement disorder characterized by intermittent muscle contractions [7, 8]. Dystonia occurs either as an isolated condition or accompanied by other disorders such as Parkinsonism, and is closely linked to PD. Dystonia is seen in over $30 \%$ of patients with PD and often even before the onset of Parkinsonism [9]. Dystonia is common in PD patients whose age of onset is $<40$, and it most commonly affects the lower limbs $[10,11]$.

Several previous studies have found that patients carrying mutations in dystonia-related genes, such as GCH1

C C The Author(s). 2021 Open Access This article is licensed under a Creative Commons Attribution 4.0 International License, which permits use, sharing, adaptation, distribution and reproduction in any medium or format, as long as you give appropriate credit to the original author(s) and the source, provide a link to the Creative Commons licence, and indicate if changes were made. The images or other third party material in this article are included in the article's Creative Commons licence, unless indicated otherwise in a credit line to the material. If material is not included in the article's Creative Commons licence and your intended use is not permitted by statutory regulation or exceeds the permitted use, you will need to obtain permission directly from the copyright holder. To view a copy of this licence, visit http://creativecommons.org/licenses/by/4.0/ The Creative Commons Public Domain Dedication waiver (http://creativecommons.org/publicdomain/zero/1.0/) applies to the data made available in this article, unless otherwise stated in a credit line to the data. 
and $T H$, displayed features of Parkinsonism in addition to dystonia [12, 13]. Even in patients with pure Parkinsonism (without dystonia), the frequency of rare GCH1 variants were higher than in controls, indicating that variants in $\mathrm{GCH} 1$ may be associated with a higher risk of PD. [14] Extending current understandings of the COL6A3 gene, we report here compound heterozygous mutations in the COL6A3 gene in an early-onset PD patient. To further investigate the relationship between COL6A3 and PD, we screened for COL6A3 mutations in a Chinese cohort.

\section{Methods and materials Subjects}

A total of 173 cases of sporadic PD (diagnosed by a specialist in movement disorders following the MDS diagnostic criteria [3]) were recruited from the Second Affiliated Hospital of Medicine College, Zhejiang University, between January 2016 and June 2019. Of these, 81 were defined as early onset PD (EOPD) with age at onset $\leq 50$ years old. The remaining 92 were late onset PD (LOPD) with age at onset $>50$ years old A gene sequencing panels test of PD was performed in all patients and no pathogenic variants in established Mendelian Parkinson's disease genes such as SNCA, LRRK2, VPS35, PARK2/parkin, PARK7/DJ-1, or PINK1 were found. The index patient was a 43 years old male with no remarkable medical history or family history from Chinese Han population. In addition, 200 demographically-matched healthy controls were included.

\section{Sample preparation and sequencing}

Genomic DNA of the patients and controls was isolated from peripheral leukocytes using standard protocols. Whole sequences of the selected genes were captured with a SureSelect Human All Exon $50 \mathrm{Mb}$ kit (Agilent Technologies). Sequencing was conducted as $150 \mathrm{bp}$ paired-end runs on an Illumina Nova Seq 5000 system to a 300-fold depth of coverage. AfterQC [15] was used to processes the raw data, including filtering out and trimming bad reads. Then, sequence reads were mapped to the human genome assembly GRCh37/hg19 using Burrows-Wheeler Aligner 16. ANNOVAR software was used to annotate the variants [16].

\section{Criteria for pathogenicity of rare variants}

To determine the deleterious variants of the COL6A3 gene, we filtered the variants found in our cohort using the following algorithm: 1) identify rare nonsynonymous variants with a minor allele frequency of < $1 \%$ or "not available" in the Genome Aggregation Database East Asia [17] or the 1000 Genomes Project [18]. Variants in the exon region were selected for further evaluation since they are more likely to have a negative effect on protein structure and function. 2) Use an integrated genetic and clinical database, the VarCards [19], for preliminary evaluation of the deleterious effect of the variants. Those variants predicted to be deleterious by at least 15 tools were considered potentially pathogenic. 3 ) Screen the variants in the control population.

Amino acid conservation analysis using multiple sequence alignment of COL6A3 protein sequences from different species was performed by ClustalX [20].

The 3D protein structures of the wild-type and variant proteins were predicted using Phyre2 [21] and visualized by PyMOL (The PyMOL Molecular Graphics System v2.0, Schrödinger, LLC). The effects of missense variants on protein structure were evaluated by Missense3D [22].

\section{Statistical analysis}

Before genetic analysis was performed, we carried out a Hardy-Weinberg Equilibrium (HWE) test via chisquared test in the control group [23].

The sequence kernel association test optimal (SKAT$O$ [24],) was implemented in $R$ (version3.6.2, The $R$ Foundation) using SKAT v2.0 to determine the difference between PD cases and controls in aggregate burden of rare $C O L 6 A 3$ gene variants. Gender was adjusted as a covariate. Power calculations were performed using functions in the SKAT-O R packages with disease prevalence of PD set as 1.7\%, significant lever set as 0.05 and causal percent of the variants set as 10,30 and 50\% respectively.

\section{Results}

\section{General information}

Our index patient was a 43-year-old male with no remarkable past medical history. He developed a mild gait difficulty 4 years ago. His symptoms worsened over time and he gradually experienced muscle rigidity and clumsiness. Physical examination showed bilateral rigidity and bradykinesia without resting tremor or dystonia. Dopamine transporter positron emission tomography (DATPET) revealed reduced tracer uptake bilaterally, mainly in the putamen, indicating nigrostriatal dopaminergic denervation. He responded well to levodopa therapy $(300 \mathrm{mg} /$ day). Whole-exome sequencing didn't found any mutation in known PD genes, however, revealed two heterozygous recessive variants in the COL6A3 gene (p.A769T and p.D1674N). The p.A769T variant was reported on ClinVar with an interpretation of uncertain significance or likely benign, while the other variant p.D1674N was not previously reported on ClinVar. His pedigree chart and DAT-PET scan result are shown in Fig. 1.

General information about our cohort were presented in Table 1. Among the PD patients, 12 patients were 


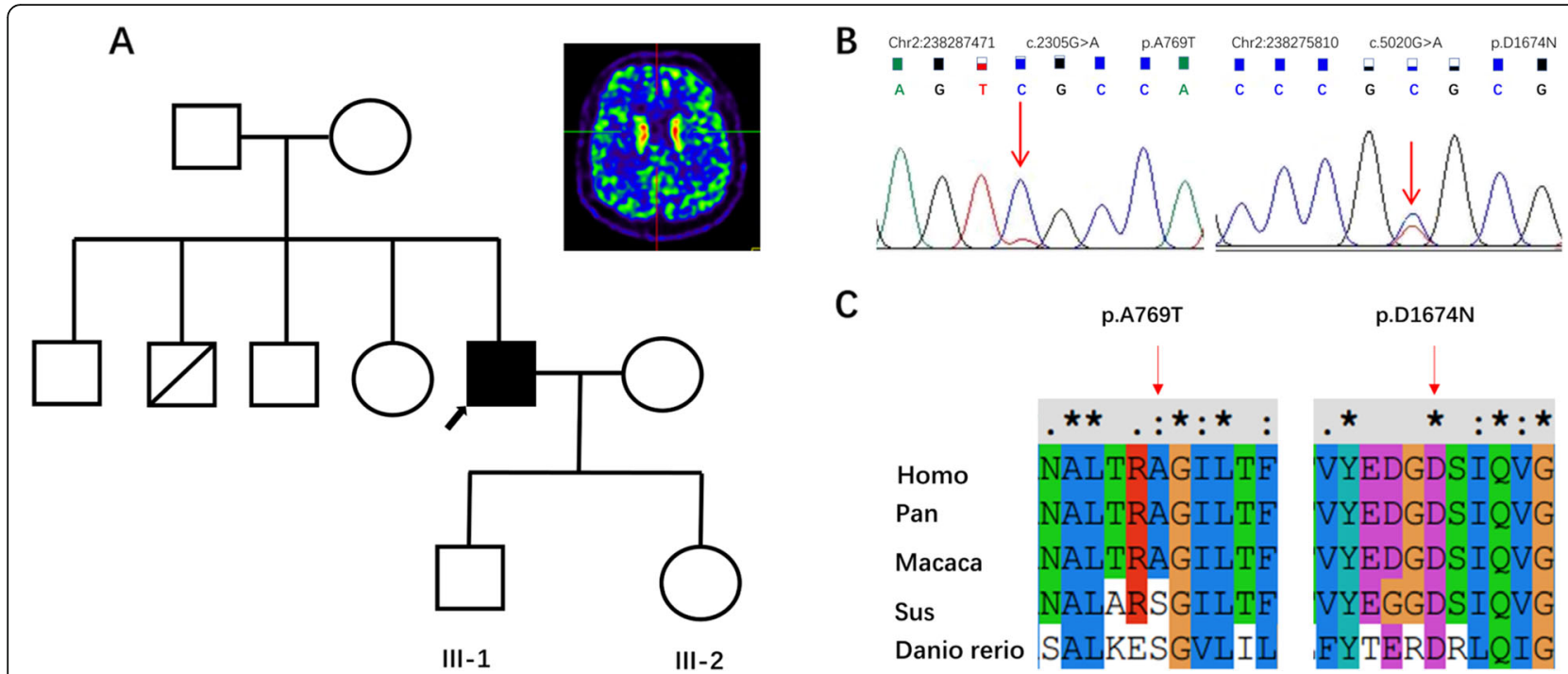

Fig. 1 a: Pedigrees and DAT-PET scan images of the index patient. II-2 died of liver cancer b: sanger sequencing result. c: multiple sequence alignment conducted by ClustalX. Asterisk (*) indicates positions that have a single, fully conserved residue. Colon (:) indicates conservation between groups of strongly similar properties. Period (.) indicates conservation between groups of weakly similar properties

recorded with dystonia and the prevalence was higher in EOPD group than LOPD group.

\section{Variant analysis}

Most genotype frequencies in the control group were in agreement with the HWE principle $(p>0.05)$, indicating our data are free from sample level substructure and genotyping error.

According to our filtering procedure, 21 rare nonsynonymous variants were selected (data not shown). In silico predicting tools further identified seven patients with variants of $C O L 6 A 3$ likely to have a pathogenic effect (Table 2). Of these patients, four were in the EOPD group and the other three in the LOPD group. Only two patients with the variants p.A1031T and p.R1656Q presented with foot dystonia. Detailed clinical features of the other patients are shown in Table 3.

Multiple sequence alignment by ClustalX showed that four variants were fully conserved (p.R928H, p.A1031T, p.G1898R and p.F1236S), indicating variants in these loci may have an effect on protein function (Fig. 2). However, 3D structure prediction of all the variants and the wild type detected no structural alterations (Fig. 3).

Of the seven variants we identified, two were previously reported on Clinvar. These two, rs114322958 and rs545819982, were recorded as benign and uncertain significance respectively for Bethlem myopathy 1 .

SKAT-O analysis showed significant associations for the COL6A3 gene between PD patients and controls considering the 7 likely damaging variant we identified above after adjusting for gender. $(P=0.038)$. Statistical powers were $13.2,19.2$ and $39.5 \%$ respectively when assuming the casual percent to be 10,30 and $50 \%$.

\section{Discussion}

The COL6A3 gene, encodes a component of type VI collagen, which is a flexible protein in the extracellular space [25]. Previous studies [26] have shown that mutation in COL6A genes (COL6A 1-3) is associated with

Table 1 summary of basic information of PD and Control

\begin{tabular}{|c|c|c|c|c|c|}
\hline & \multicolumn{3}{|l|}{ PD } & \multirow[t]{2}{*}{ Control } & \multirow[t]{2}{*}{$P$} \\
\hline & All & EOPD & LOPD & & \\
\hline Number & 173 & 81 & 92 & 200 & . \\
\hline Male & 93 (53.8\%) & 42 (51.9\%) & $51(55.4 \%)$ & 102 (51\%) & 0.61 \\
\hline$A A O \pm S D$ & $52.22 \pm 10.03$ & $44.32 \pm 5.46$ & $59.17 \pm 7.72$ & . & . \\
\hline Disease duration & $3.35 \pm 3.09$ & $3.81 \pm 3.82$ & $2.93 \pm 2.20$ & . & \\
\hline Dystonia feature & $12(6.9 \%)$ & $8(9.8 \%)$ & $4(4.3 \%)$ & & \\
\hline
\end{tabular}

EOPD is defined in this study as PD patients whose age of onset is $\leq 50$, while LOPD is defined as patients whose age of onset is $>50$. $P$ value refer to comparison between control and all PD patients. AAO Age at onset, SD Standard deviation 
Table 2 Information of probable pathogenic variants identified in our cohort

\begin{tabular}{|c|c|c|c|c|c|c|c|c|c|c|c|c|}
\hline \multirow[t]{2}{*}{ RefSeq } & \multirow[t]{2}{*}{ Variants } & \multirow[t]{2}{*}{ Exon } & \multirow[t]{2}{*}{$\begin{array}{l}\text { Nucleotide } \\
\text { change }\end{array}$} & \multirow[t]{2}{*}{$\begin{array}{l}\text { Protein } \\
\text { change }\end{array}$} & \multicolumn{2}{|c|}{$\begin{array}{l}\text { Population MAF } \\
\text { (East Asian) }\end{array}$} & \multicolumn{3}{|c|}{ Frequency in our cohort } & \multicolumn{3}{|c|}{ In silico prediction } \\
\hline & & & & & gnomAD & $1000 \mathrm{G}$ & PD & control & P value ${ }^{\#}$ & CADD & SIFT & $\begin{array}{l}\text { Deleterious vs } \\
\text { all algorithms }\end{array}$ \\
\hline \multirow[t]{7}{*}{ NM_057166.4 } & rs545819982 & 36 & c. $5692 \mathrm{G}>\mathrm{A}$ & p.G1898R & 0 & 0.0002 & $1 / 346$ & $0 / 400$ & 0.038 & 20.5 & 0 & $18: 23$ \\
\hline & rs369317566 & 31 & c.5204G > A & p.R1735Q & 0 & . & $1 / 346$ & $0 / 400$ & & 24.3 & 0.365 & $16: 23$ \\
\hline & rs370862741 & 29 & c.5095C > T & p.R1699C & 0.0001 & 0 & $1 / 346$ & $0 / 400$ & & 24.4 & 0.055 & 19:23 \\
\hline & rs779508804 & 27 & $c .4967 G>A$ & p.R1656Q & 0.0001 & . & $1 / 346$ & $2 / 400$ & & 24.5 & 0.053 & $16: 23$ \\
\hline & rs770876436 & 12 & c.3707 T > C & p.F1236s & 0.0003 & . & $1 / 346$ & $0 / 400$ & & 24.6 & 0.002 & $16: 23$ \\
\hline & rs114322958 & 11 & c.3091G > A & p.A1031T & 0.0063 & 0.0008 & $1 / 346$ & $9 / 400$ & & 25.5 & 0.005 & $20: 24$ \\
\hline & rs115765346 & 10 & $c .2783 G>A$ & p.R928H & 0.0001 & 0 & $1 / 346$ & $2 / 400$ & & 27.3 & 0.002 & $22: 23$ \\
\hline
\end{tabular}

algorithms or tools include PolyPhen2_HDIVPolyPhen2_HVAR, LRT, MutationTaster, MutationAssessor, FATHMM, PROVEAN, MetaSVM, MetaLR, VEST3, M-CAP, CADD, GERP++, DANN, fathmm-MKL, Eigen, GenoCanyon, fitCons, PhyloP, PhastCons, SiPhy and REVEL

${ }^{\#} P$ value calculated via SKAT-O

Bethlem myopathy and Ullrich congenital muscular dystrophy. Now it is believed that these two diseases may be at one end of a phenotypic spectrum, mainly manifesting as muscle weakness and joint contractures [27].

Using whole-exome sequencing, Zech et al. [6] recently reported recessive mutations in the COL6A3 gene in association with early-onset isolated dystonia. Clinical symptoms varied from focal dystonia, mild cervical dystonia, mild segmental dystonia and mild generalized dystonia to severe generalized dystonia. A previous study by Zech et al. [28] detected five variants in five early-onset isolated dystonia patients, and found that at least one of the homozygous variants is located in exon 41 or 42 . Furthermore, experiments in Zebrafish embryos and the mouse brain showed the exon skipping mutation in exon 41 resulted in the development of segmental dystonia, without any muscular disease. Thus, they concluded that variants in COL6A3 may cause dystonia by affecting the extracellular matrix in the central nervous system, and that exons 41 and 42 are hotspots for mutation [6].
However, the role of COL6A3 mutation in isolated dystonia had been challenged by Lohmann et al. [27], who screened 955 patients with combined or isolated dystonia. They only identified one biallelic mutation in a patient with Parkinsonism and dystonia. This patient also carried homozygous mutations in the PINK1 gene, which are considered to be associated with early-onset Parkinsonism. Panda et al. also reported an early-onset isolated dystonia case with two pathogenic compound heterozygous loss-of-function mutations in exons 10 and 12 of COL6A3 [29].

Dystonia can be seen in both early- and late-onset PD patients, and can occur precede or after parkinsonism [30]. Two of the seven patients we identified carrying these possible deleterious variants presented with dystonia feature. We assume it may be due to the relatively short disease duration (mean 3.7 years).

In the present study, we reported two recessive mutations (p.A769T and p.D1674N) in the COL6A3 gene in our index PD patient. The variants are located in exons

Table 3 Clinical manifestation of patients with COL6A3 variants that are likely pathogenic

\begin{tabular}{|c|c|c|c|c|c|c|}
\hline Gender & $\begin{array}{l}\text { Age of } \\
\text { onset }\end{array}$ & $\begin{array}{l}\text { Amino Acid } \\
\text { Change }\end{array}$ & $\begin{array}{l}\text { Disease } \\
\text { duration }\end{array}$ & Parkinsonian features & $\begin{array}{l}\text { Dystonia } \\
\text { feature }\end{array}$ & $\begin{array}{l}\text { Levodopa } \\
\text { response }\end{array}$ \\
\hline Female & 59 & $\mathrm{R} 928 \mathrm{H}$ & 5 & $\begin{array}{l}\text { bradykinesia and rigidity, Loss of smell, sleep } \\
\text { disturbance and constipation }\end{array}$ & none & good \\
\hline Female & 57 & A1031T & 2 & $\begin{array}{l}\text { right lower limb tremor and slightly impaired } \\
\text { gait }\end{array}$ & right foot dystonia & not taken \\
\hline Male & 47 & F1236S & 2 & right limbs resting tremor & none & not taken \\
\hline Female & 47 & R1656Q & 4 & $\begin{array}{l}\text { tremor, rigidity and bradykinesia, mainly in } \\
\text { the right limb; constipation }\end{array}$ & right foot dystonia & good \\
\hline Male & 49 & R1699C & 3 & $\begin{array}{l}\text { right limb resting tremor and bradykinesia; } \\
\text { loss of smell and fatigue }\end{array}$ & none & good \\
\hline Male & 45 & R1735Q & 3 & bradykinesia and impaired gait, pain & none & good \\
\hline Male & 56 & G1898R & 7 & $\begin{array}{l}\text { hallucinations, dementia, insomnia and } \\
\text { slurred speech, bradykinesia and rigidity }\end{array}$ & none & not good \\
\hline
\end{tabular}




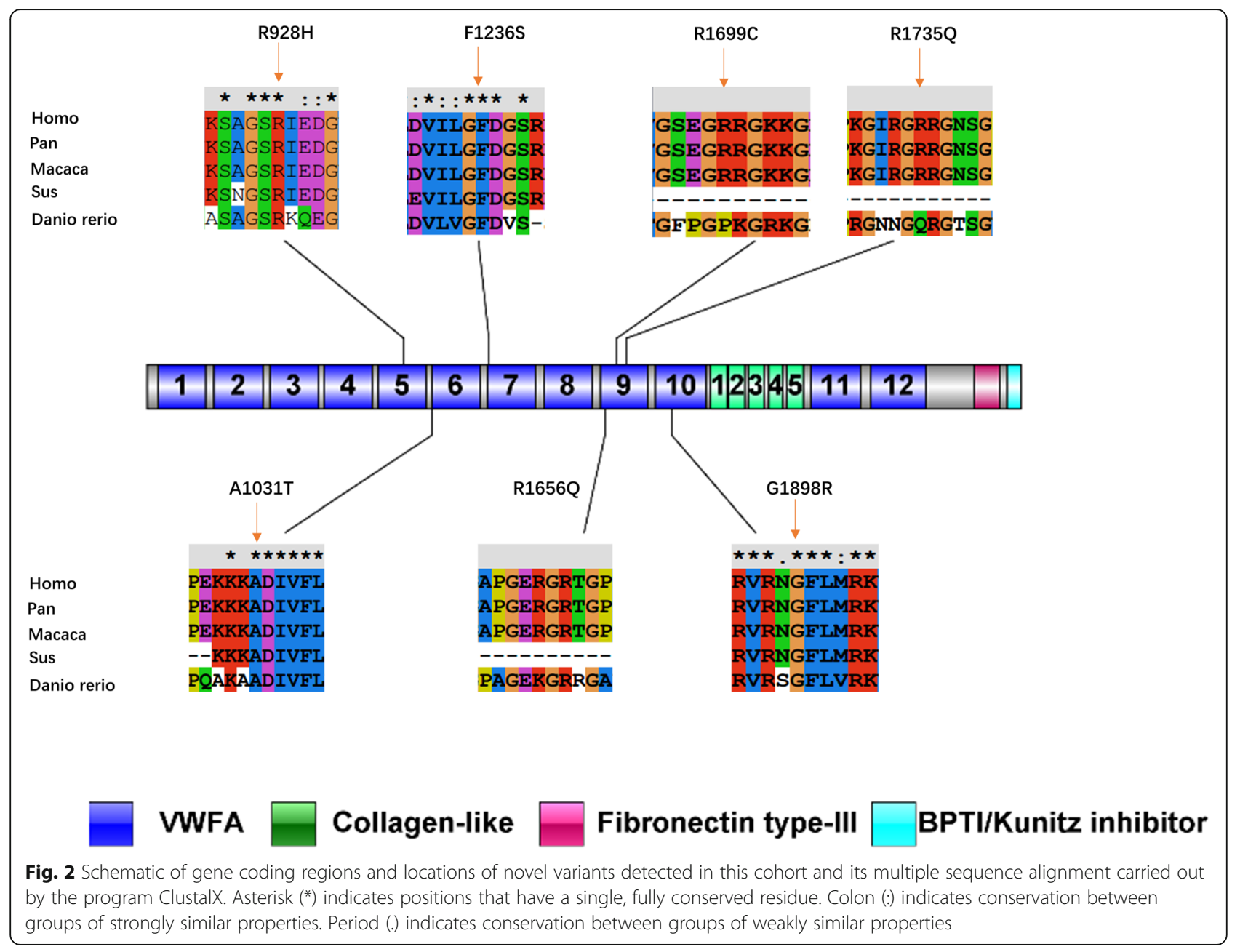

6 and 8 , in contrast to the previous study. However, since the patient currently shows no symptoms of dystonia, we assume variants in some region of COL6A3 may have an association with PD. As a result, we identified seven likely pathogenic variants in $C O L 6 A 3$, but none of them were located in exon 41 or 42 as previously reported. In addition, two patients who carried the variants p.A1031T and p.R1656Q presented with dystonia. SKAT-O analysis showed significant aggregate burden between patients and controls, indicating that variants in the COL6A3 gene may increase the genetic burden in PD.

Conventional single-variant test may not be appropriate in our cohort because of small sample size and variants' low frequencies. Thus we adapted the SKAT-O to investigate the associations of variants and phenotypes. SKAT-O combined the burden test and SKAT to maximize the power [31]. Besides, by way of smallsample adjustment method of SKAT-O, we can properly control the type I error due to small sample size. However, SKAT-O also has its limitation: in the scenario that there are more neutral variants than actual deleterious variants, it may be slightly less powerful [32].

Our study suggests that variants in the COL6A3 gene may increase susceptibility to PD. Further studies on the function and mechanism of COL6A3 and other dystonia-related genes are needed to unravel the complexity of the association between PD and dystonia.

There are several limitations in our study. Our cohort only had a small sample size and mainly consisted of patients and controls from southeast China of Han Chinese populations. Therefore, the current study may produce false-positive results, or over-estimate the magnitude of the association, and the result might be population specific. Besides, population stratification might still exist even our participants nearly comes from the same region, leading to false-positive or false-negative findings. Therefore, future studies adjusting for population stratification via means of principal component analysis or multi-dimensional scaling are needed. Genetic relatedness might as well affect our conclusion since participant from both case or control may share alleles 


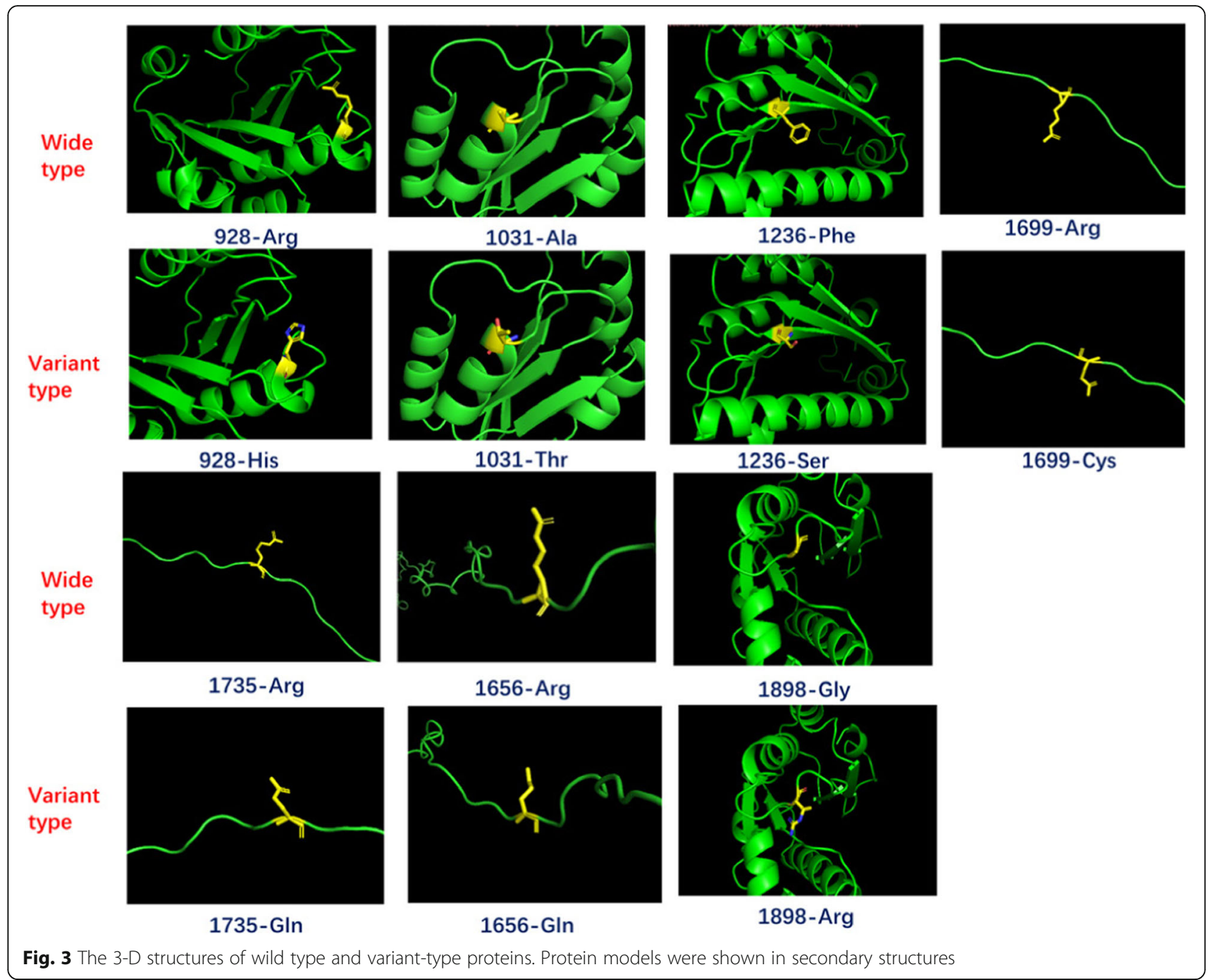

due to kinship rather than different PD condition. Methods such as kinship coefficients or identity by descent (IBD) might further be implemented to count for this potential bias. Currently, there are few studies of the relationship between COL6A3 and PD. Further clinical studies with a larger sample size more and diverse demographic background are warranted, along with basic studies exploring the biological function of COL6A3 and its associated pathways.

\section{Acknowledgements}

Not applicable.

\section{Authors' contributions}

CYJ and JLP conceived the idea and drafted the manuscript. CYJ, RZ ZHL, NJX, JT, XZY contributed to the collection and interpretation of the data. YC, TG, YQY, YF, YPY helped in designing the study and collecting data. Manuscript revisions were completed by both JLP and BRZ. All authors read and approved the final manuscript.

\section{Funding}

This work was supported by the National Natural Science Foundation of China [grant numbers 81520108010 and 81771216], the Key Research and
Development Program of Zhejiang Province [grant number 2020C03020] and the Natural Science Foundation of Zhejiang Provincial [No. LY18H090003].

Availability of data and materials

The datasets used and/or analyzed during the current study are available from the corresponding author on reasonable request.

\section{Declarations}

Ethics approval and consent to participate

The study was approved by the Medical Ethics Committee of the Second Affiliated Hospital of Zhejiang University School of Medicine. All subjects completed informed consent for participation and publication of potential identifying information or images in an online open-access publication before the evaluation and original sample collection. All methods were carried out in accordance with relevant guidelines and regulations.

Consent for publication

Signed consent for this publication has been obtained from all participating subjects.

Competing interests

The authors disclose no conflicts of interest regarding this manuscript. 
Received: 5 February 2021 Accepted: 20 April 2021

Published online: 08 May 2021

\section{References}

1. Ascherio A, Schwarzschild MA. The epidemiology of Parkinson's disease: risk factors and prevention. Lancet Neurol. 2016;15(12):1255-70.

2. Poewe W, Seppi K, Tanner CM, Halliday GM, Brundin P, Volkmann J, et al. Parkinson disease. Nat Rev Dis Primers. 2017;3:17013. https://doi.org/10.103 8/nrdp.2017.13.

3. Postuma RB, Berg D, Stern M, Poewe W, Olanow CW, Oertel W, et al. MDS clinical diagnostic criteria for Parkinson's disease. Mov Disord. 2015;30(12): 1591-601. https://doi.org/10.1002/mds.26424.

4. Chaudhuri KR, Schapira AHV. Non-motor symptoms of Parkinson's disease: dopaminergic pathophysiology and treatment. Lancet Neurol. 2009;8(5): 464-74. https://doi.org/10.1016/s1474-4422(09)70068-7.

5. Demir E, Sabatelli P, Allamand V, Ferreiro A, Moghadaszadeh B, Makrelouf M, et al. Mutations in COL6A3 cause severe and mild phenotypes of Ullrich congenital muscular dystrophy. Am J Human Gen. 2002;70(6):1446-58. https://doi.org/10.1086/340608.

6. Zech M, Lam DD, Francescatto L, Schormair B, Salminen AV, Jochim A, et al. Recessive mutations in the alpha3 (VI) collagen gene COL6A3 cause earlyonset isolated dystonia. Am J Hum Genet. 2015;96(6):883-93. https://doi. org/10.1016/j.ajhg.2015.04.010.

7. Frucht SJ. The definition of dystonia: current concepts and controversies. Mov Disord. 2013;28(7):884-8. https://doi.org/10.1002/mds.25529.

8. Albanese A, Bhatia K, Bressman SB, Delong MR, Fahn S, Fung VS, et al. Phenomenology and classification of dystonia: a consensus update. Mov Disord. 2013;28(7):863-73. https://doi.org/10.1002/mds.25475.

9. Kidron D, Melamed EJN. Forms of dystonia in patients with Parkinson's disease. Neurology. 1987;37(6):1009.

10. Ishikawa A, Miyatake T. A family with hereditary juvenile dystoniaparkinsonism. Mov Disord. 1995;10(4):482-8.

11. Carella F, Giovannini P, Girotti F, Testa D, Caraceni T. Dystonia and Parkinson's disease. J Neurol. 1993;60:558-61.

12. Wijemanne S, Jankovic J. Dopa-responsive dystonia—clinical and genetic heterogeneity. Nat Rev Neurol. 2015;11(7):414

13. Phukan J, Albanese A, Gasser T, Warner T. Primary dystonia and dystonia-plus syndromes: clinical characteristics, diagnosis, and pathogenesis. Lancet Neurol. 2011;10(12):1074-85. https://doi.org/10.101 6/S1474-4422(11)70232-0.

14. Mencacci NE, Isaias IU, Reich MM, Ganos C, Plagnol V, Polke JM, et al. Parkinson's disease in GTP cyclohydrolase 1 mutation carriers. Brain. 2014; 137(Pt 9):2480-92. https://doi.org/10.1093/brain/awu179.

15. Chen S, Huang T, Zhou Y, Han $Y, X u$ M, Gu J. AfterQC: automatic filtering, trimming, error removing and quality control for fastq data. BMC Bioinform. 2017;18(Suppl 3):80. https://doi.org/10.1186/s12859-017-1469-3.

16. Yang $\mathrm{H}$, Wang K. Genomic variant annotation and prioritization with ANNOVAR and wANNOVAR. Nat Protoc. 2015;10(10):1556-66. https://doi. org/10.1038/nprot.2015.105.

17. Karczewski KJ, Francioli LC, Tiao G, Cummings BB, Alföldi J, Wang Q, et al. Variation across 141,456 human exomes and genomes reveals the spectrum of loss-of-function intolerance across human protein-coding genes. BioRxiv. 2019;1:531210. https://doi.org/10.1101/531210\%J.

18. Genomes Project C, Auton A, Brooks LD, Durbin RM, Garrison EP, Kang HM, et al. A global reference for human genetic variation. Nature. 2015; 526(7571):68-74. https://doi.org/10.1038/nature15393.

19. Li J, Shi L, Zhang K, Zhang Y, Hu S, Zhao T, et al. VarCards: an integrated genetic and clinical database for coding variants in the human genome. Nucleic Acids Res. 2017;46(D1):D1039-D48. https://doi. org/10.1093/nar/gkx1039\%J.

20. Larkin MA, Blackshields G, Brown NP, Chenna R, McGettigan PA, McWilliam $\mathrm{H}$, et al. Clustal W and Clustal X version 2.0. Bioinformatics (Oxford, England). 2007;23(21):2947-8

21. Kelley LA, Mezulis S, Yates CM, Wass MN, Sternberg MJE. The Phyre2 web portal for protein modeling, prediction and analysis. Nat Protoc. 2015;10(6): 845-58. https://doi.org/10.1038/nprot.2015.053.

22. Ittisoponpisan S, Islam SA, Khanna T, Alhuzimi E, David A, Sternberg MJE. Can predicted protein 3D structures provide reliable insights into whether missense variants are disease associated? J Mol Biol. 2019:431(11):2197-212. https://doi.org/10.1016/j.jmb.2019.04.009.
23. Ziegler A, Van Steen K, Wellek S. Investigating hardy-Weinberg equilibrium in case-control or cohort studies or meta-analysis. Breast Cancer Res Treat. 2011;128(1):197-201. https://doi.org/10.1007/s10549-010-1295-z.

24. Wu MC, Lee S, Cai T, Li Y, Boehnke M, Lin X. Rare-variant association testing for sequencing data with the sequence kernel association test. Am J Hum Genet. 2011;89(1):82-93. https://doi.org/10.1016/j.ajhg.2011.05.029.

25. VON DER, MARK H, AUMAILLEY M, WICK G, FLEISCHMAJER R, Timpl R. Immunochemistry, genuine size and tissue localization of collagen VI. Eur J Biochem. 1984;142(3):493-502.

26. Bonnemann CG. The collagen VI-related myopathies: muscle meets its matrix. Nat Rev Neurol. 2011;7(7):379-90. https://doi.org/10.1038/nrneurol.2011.81.

27. Lampe AK, Bushby KM. Collagen VI related muscle disorders. J Med Genet. 2005:42(9):673-85. https://doi.org/10.1136/jmg.2002.002311.

28. Jochim A, Zech M, Gora-Stahlberg G, Winkelmann J, Haslinger B. The clinical phenotype of early-onset isolated dystonia caused by recessive COL6A3 mutations (DYT27). Mov Disord. 2016;31(5):747-50. https://doi.org/10.1002/ mds.26501.

29. Panda PK, Sharawat IK. COL6A3 mutation associated early-onset isolated dystonia (DYT)-27: report of a new case and review of published literature. Brain Dev. 2020. https://doi.org/10.1016/j.braindev.2020.01.004.

30. Tolosa E, Compta Y. Dystonia in Parkinson's disease. J Neurol. 2006; 253(Suppl 7):VII7-13. https://doi.org/10.1007/s00415-006-7003-6.

31. Lee S, Emond MJ, Bamshad MJ, Barnes KC, Rieder MJ, Nickerson DA, et al. Optimal unified approach for rare-variant association testing with application to small-sample case-control whole-exome sequencing studies. Am J Hum Genet. 2012:91(2):224-37. https://doi.org/10.1016/j.ajhg.2012.06.007.

32. Moutsianas L, Agarwala V, Fuchsberger C, Flannick J, Rivas MA, Gaulton KJ, et al. The power of gene-based rare variant methods to detect diseaseassociated variation and test hypotheses about complex disease. PLoS Genet. 2015;11(4):e1005165. https://doi.org/10.1371/journal.pgen.1005165.

\section{Publisher's Note}

Springer Nature remains neutral with regard to jurisdictional claims in published maps and institutional affiliations.

Ready to submit your research? Choose BMC and benefit from:

- fast, convenient online submission

- thorough peer review by experienced researchers in your field

- rapid publication on acceptance

- support for research data, including large and complex data types

- gold Open Access which fosters wider collaboration and increased citations

- maximum visibility for your research: over $100 \mathrm{M}$ website views per year

At $\mathrm{BMC}$, research is always in progress.

Learn more biomedcentral.com/submissions 